Article

\title{
Predictive Effects of Inflammatory Scores in Patients with BCLC 0-A Hepatocellular Carcinoma after Hepatectomy
}

\author{
Pao-Yuan Huang ${ }^{1}{ }^{1}$, Chih-Chi Wang ${ }^{2}$, Chih-Che Lin ${ }^{2}$, Sheng-Nan Lu ${ }^{1,3}$, Jing-Houng Wang ${ }^{1}$, \\ Chao-Hung Hung ${ }^{1}$, Kwong-Ming Kee ${ }^{1}$, Chien-Hung Chen ${ }^{1}$, Kuang-Den Chen ${ }^{4}$, \\ Tsung-Hui $\mathrm{Hu}^{1}$ and Ming-Chao Tsai ${ }^{1,5, *}$ \\ 1 Division of Hepato-Gastroenterology, Department of Internal Medicine, Kaohsiung Chang Gung Memorial \\ Hospital and Chang Gung University College of Medicine, Kaohsiung 83301, Taiwan; \\ paoyuan813@gmail.com (P.-Y.H.); juten@ms17.hinet.net (S.-N.L.); jinghoung2001@yahoo.com.tw (J.-H.W.); \\ chh4366@yahoo.com.tw (C.-H.H.); kee.kkm@gmail.com (K.-M.K.); e580306@ms31.hinet.net (C.-H.C.); \\ dr.hu@msa.hinet.net (T.-H.H.) \\ 2 Liver Transplantation Program and Department of Surgery, Kaohsiung Chang Gung Memorial Hospital, \\ Chang Gung University College of Medicine, Kaohsiung 83301, Taiwan; ufel4996@gmail.com (C.-C.W.); \\ immunologylin@gmail.com (C.-C.L.) \\ 3 Division of Hepato-Gastroenterology, Department of Internal Medicine, Chiayi Chang Gung Memorial \\ Hospital, Chiayi 61363, Taiwan \\ 4 Center for Translational Research in Biomedical Sciences, Liver Transplantation Program and Department of \\ Surgery, Kaohsiung Chang Gung Memorial Hospital and Chang Gung University College of Medicine, \\ Kaohsiung 83301, Taiwan; dennis8857@gmail.com \\ 5 Graduate Institute of Clinical Medical Sciences, Chang Gung University College of Medicine, \\ Taoyuan 33302, Taiwan \\ * Correspondence: tony0779@gmail.com; Tel.: +886-7-731-7123 (ext. 8310); Fax: +886-7-732-2402
}

Received: 8 September 2019; Accepted: 10 October 2019; Published: 14 October 2019

\begin{abstract}
Background: Inflammatory markers are regarded as prognostic factors of the outcomes of hepatocellular carcinoma (HCC). Examples include the neutrophil-to-lymphocyte ratio (NLR); platelet to lymphocyte ratio (PLR); the albumin and lymphocyte counts used in the prognostic nutritional index (PNI); and the neutrophil, lymphocyte, and platelet counts used in the systemic immune-inflammation index (SII). This study evaluates the effects of PNI, NLR, PLR, and SII to predict recurrence and survival in patients with Barcelona Clinic Liver Cancer (BCLC) stages 0-A of HCC after hepatectomy. Methods: This retrospective study was conducted at Kaohsiung Chung-Gung Memorial Hospital, Taiwan. The study enrolled 891 patients (77.9\% males; mean age $58.53 \pm 11.60$ years) with BCLC stage 0/A HCC undergoing hepatectomy between 2001 and 2016. PNI, NLR, PLR and SII were measured before hepatectomy. Results: High NLR $(>1.8)$ was adversely associated with overall survival $(p=0.032)$. Low PNI $(\leq 45)$ was adversely associated with overall survival and disease-free survival $(p<0.001)$. Low SII $(\leq 45)$ also had an adverse association with overall survival $(p=0.008)$ and disease-free survival $(p<0.001)$. Diabetes mellitus, cirrhosis, microvascular invasion, low PNI $(\leq 45)$, and low SII $(\leq 160)$ were independently associated with poor overall survival in a multivariate analysis. HCV infection, diabetes mellitus, cirrhosis, microvascular invasion, low PNI, and low SII were independent prognostic factors of recurrent HCC. The combined use of PNI and SII provided improved prognostic information. Conclusions: Low PNI and low SII are significantly poor prognostic factors for overall survival and recurrence in patients with BCLC 0-A hepatocellular carcinoma after hepatectomy.
\end{abstract}

Keywords: hepatocellular carcinoma; hepatectomy; inflammatory scores 


\section{Introduction}

Liver cancer is the sixth most commonly diagnosed cancer and the fourth leading cause of cancer death worldwide as of 2018. Hepatocellular carcinoma (HCC) comprises 75-85\% of primary liver cancer cases [1]. The management of HCC depends on the tumor stage at diagnosis and liver function. Current management strategies involve resection, liver transplantation (LT), radiofrequency ablation (RFA), transarterial embolization (TAE)/transarterial chemoembolization (TACE), radiation therapy, or systemic therapy [2,3]. Patients are considered to have resectable tumors if they have one to three unilobar lesions with an upper limit of $5 \mathrm{~cm}$ for a single lesion and $3 \mathrm{~cm}$ for more than one lesion; no extrahepatic metastasis or macrovascular invasion; and little or no portal hypertension [2].

Hepatectomy is a potentially curative treatment for $\mathrm{HCC}$, but the long-term prognosis remains unsatisfactory due to the high incidence of recurrence (50-60\%) [4-6]. Prognostic factors for recurrence and survival after resection include tumor size, $\alpha$-fetoprotein level, tumor differentiation, microvascular invasion, cirrhosis, surgical margin, and metabolic syndrome [6-8]. Recently, the associations between inflammatory markers and the prognosis of HCC have been actively explored, and systemic inflammation has been thought to be related to poor outcomes. The reason is that inflammatory responses play critical roles in tumorigenesis, including initiation, promotion, angiogenesis, invasion, and metastasis [9], and an inflammatory microenvironment is an important condition for tumors [10].

Systemic inflammatory responses have been investigated using markers such as the neutrophil-to-lymphocyte ratio (NLR) [11-14], platelet to lymphocyte ratio (PLR) [15-17], albumin and lymphocyte counts used in the prognostic nutritional index (PNI) [18-20], and neutrophil, lymphocyte, and platelet counts used in the systemic immune-inflammation index (SII) [21,22]. To date, most studies have evaluated only one of the inflammatory parameters. Therefore, a comprehensive evaluation of the prognostic values of the inflammatory markers would be valuable for patients with HCC. The aim of this study is to evaluate the effects of inflammatory markers to predict recurrence and survival in HCC patients who have Barcelona Clinic Liver Cancer (BCLC) grades 0-A and are receiving hepatectomy.

\section{Materials and Methods}

\subsection{Ethics Statement}

The study protocol was approved by the institutional review board and the ethics committee of Chang Gung Memorial Hospital (201901103B0). The ethics committee waived the requirement for informed consent for this study, and all the data were analyzed anonymously.

\subsection{Data Sources}

This retrospective study enrolled patients with newly diagnosed HCC who underwent surgical intervention between January 2001 and June 2016 at Kaohsiung Chung-Gung Memorial Hospital. HCC was diagnosed based on histological evidence or classical imaging features according to the guidelines of the American Association for the Study of the Liver [23]. The staging of tumors was determined according to the BCLC staging classification [24]. Patients who had RFA or TAE before resection, LT after resection, or BCLC stage B or C were excluded from the study (Figure 1). Surgical resection for tumors in BCLC stage 0 or A is the widely accepted standard treatment. However, surgical treatment for BCLC stage B or C HCC remains controversial. Recently, the management of HCC has tended to involve a multidisciplinary approach, such as RFA or TACE combined with surgery, etc. Because RFA and TACE are associated with the induction of inflammation and immunological responses, it might have some degree of influence on inflammatory indicators. Hence, only treatment-naïve HCC patients were enrolled in our study. LT was believed to cure both the tumor and the underlying cirrhosis at the same time in well-selected patients, which also have an influence on the survival. Therefore, those who received salvage LT were excluded [25]. 


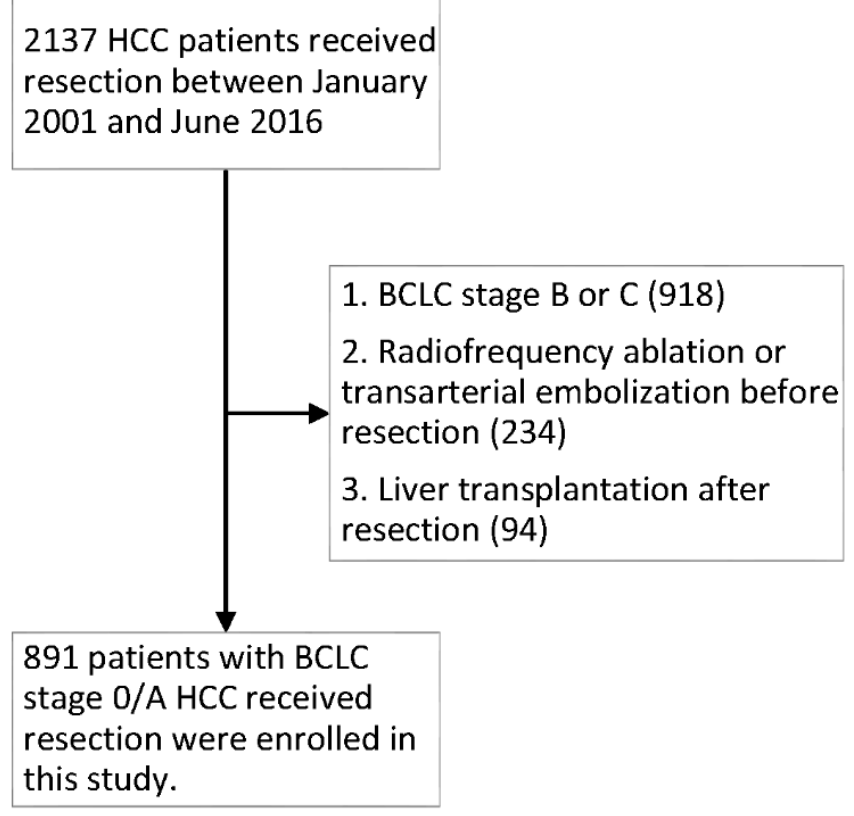

Figure 1. Flow chart of patients included in this study. HCC, hepatocellular carcinoma; BCLC, Barcelona Clinic Liver Cancer.

\subsection{Methods}

Patient demographics and clinical characteristics were obtained from the reviewed medical records, including complete blood counts, albumin, $\alpha$-fetoprotein level, Child-Turcotte-Pugh (CTP) class, date of diagnosis, status of viral hepatitis, tumor staging by BCLC, duration of follow-up, and outcomes. Blood tests were taken within 1 week before operation. NLR was calculated by dividing the absolute neutrophil count by the lymphocyte count, and PLR was obtained by dividing the platelet count by the lymphocyte count. PNI was calculated using the following equation: lymphocyte count $(/ \mu \mathrm{L}) \times 0.005+$ albumin $(\mathrm{g} / \mathrm{dL}) \times 10$. SII was measured as platelet count $\times$ neutrophil count/lymphocyte count $(/ \mu \mathrm{L})$ [26]. Recurrence-free survival (RFS) was defined as the period from tumor removal by resection until the detection of recurrent or metastatic disease. Overall survival (OS) was defined as the time from the diagnosis to death, last contact, or 28 February 2017.

\subsection{Statistical Analysis}

Descriptive analyses were used to determine the patients' clinicopathological characteristics at baseline. Kaplan-Meier survival curves were constructed for each variable. A Cox proportional hazard model was used for the multivariate analysis of the hazard ratio (HR). All statistical analyses were conducted using software SPSS Version 23.0. (IBM Corp., Armonk, NY, USA) A two-sided $p$ value < 0.05 was considered significant.

\section{Results}

\subsection{Clinical Characteristics}

A total of 2137 patients received hepatectomy for HCC between January 2001 and June 2016. Overall, 1246 patients were excluded due to intermediate to advanced stages (BCLC stage B or C) ( $n=$ 918), RFA or TAE before operation $(n=234)$, and liver transplantation after resection $(n=94)$. The remaining 891 patients were eligible for the analysis (Figure 1).

The mean age was 58.53 years, and the majority of patients were men $(n=694,77.9 \%)$. There were 239 patients $(27.8 \%)$ who were diabetic before surgery, and 417 patients $(46.8 \%)$ were diagnosed with cirrhosis. Cirrhosis was defined as METAVIR stage 4 fibrosis based on reports of the histopathological 
evaluation of non-tumor liver tissue obtained by surgery at the time of the resection of the tumor [27]. Most patients were classified as CTP A ( $n=819,91.9 \%)$. The median follow-up time was $5.30 \pm 3.04$ years, and a total of $433(48.6 \%)$ patients had recurrent disease during follow-up (Table 1$)$.

Table 1. Patients' baseline characteristics before hepatectomy.

\begin{tabular}{|c|c|}
\hline Number of Patients & 891 \\
\hline Median follow-up (Years) & $5.30 \pm 3.04$ \\
\hline Mean Age (Years) & $58.54 \pm 11.60$ \\
\hline HBV Infection. $n(\%)$ & $502(56.3)$ \\
\hline HCV Infection. $n(\%)$ & $311(34.9)$ \\
\hline HBV + HCV Coinfection. $n(\%)$ & $44(4.9)$ \\
\hline Male. $n(\%)$ & $694(77.9)$ \\
\hline Diabetes Mellitus. $n(\%)$ & $239(27.8)$ \\
\hline $\mathrm{AFP}>5 \mathrm{ng} / \mathrm{mL} \cdot n(\%)$ & $601(67.5)$ \\
\hline Cirrhosis. $n(\%)$ & $417(46.8)$ \\
\hline \multicolumn{2}{|l|}{ Child-Turcotte-Pugh. $n(\%)$} \\
\hline A & $819(91.9)$ \\
\hline B & $71(8)$ \\
\hline \multicolumn{2}{|l|}{ BCLC Stage. $n(\%)$} \\
\hline 0 & $125(14)$ \\
\hline A & $766(86)$ \\
\hline \multicolumn{2}{|l|}{ Tumor Differentiation. $n(\%)$} \\
\hline Well & $111(12.5)$ \\
\hline Moderate & $743(83.4)$ \\
\hline Poor & $24(2.7)$ \\
\hline HCC Recurrence. $n(\%)$ & $433(48.6)$ \\
\hline Mean time to Recurrence (years) & $3.80 \pm 3.17$ \\
\hline Mean NLR Before Surgery & $2.81 \pm 3.99$ \\
\hline NLR > 1.8 before Surgery. $n(\%)$ & $338(47.7)$ \\
\hline Mean PLR before Surgery & $102.14 \pm 67.97$ \\
\hline PLR > 120 before Surgery. $n(\%)$ & $178(25.2)$ \\
\hline Mean PNI before Surgery & $44.18 \pm 7.38$ \\
\hline $\mathrm{PNI} \leq 45$ before Surgery. $n(\%)$ & $441(55.1)$ \\
\hline Mean SII before Surgery $\left(\times 10^{9} / \mathrm{L}\right)$ & $442.23 \pm 680.78$ \\
\hline SII $\leq 160$ before Surgery. $n(\%)$ & $144(20.5)$ \\
\hline
\end{tabular}

Data are expressed as mean \pm standard deviation or number (percentage). Abbreviations: HBV: hepatitis B virus; HCV: hepatitis C virus; AFP: alpha-fetoprotein; BCLC stage: Barcelona clinic liver cancer stage; HCC: hepatocellular carcinoma; NLR: neutrophil-to-lymphocyte ratio; PLR: platelet to lymphocyte ratio; PNI: prognostic nutritional index; SII: systemic immune-inflammation index.

\subsection{Optimal Cutoff Values for Inflammatory Markers}

Each inflammatory marker was stratified according the maximum sensitivity and specificity using Youden's index. The optimal cutoff value for NLR was 1.8 (AUROC curve: $0.539 ; 95 \%$ confidence interval (CI): 0.501-0.577). The optimal cutoff value for PLR was 116.6 (AUROC curve: $0.509 ; 95 \%$ CI: 0.471-0.546). The optimal cutoff value for PNI was 42.8 (AUROC curve: $0.663 ; 95 \%$ CI: 0.626-0.698). The optimal cutoff value for SII was 160.0 (AUROC curve: 0.514; 95\% CI: 0.476-0.551) (Table 2 and Figure 2). 
Table 2. Comparisons of the areas under the curve (AUC) values and the cutoff values among the inflammatory markers.

\begin{tabular}{ccccc}
\hline & AUC & CUTOFF & SE & 95\% CI \\
\hline NLR & 0.539 & 1.809 & 0.028 & $0.501-0.577$ \\
PLR & 0.509 & 116.618 & 0.029 & $0.471-0.546$ \\
PNI & 0.663 & 42.844 & 0.026 & $0.626-0.698$ \\
SII & 0.514 & 159.984 & 0.029 & $0.476-0.551$ \\
\hline
\end{tabular}

Neutrophil-to-lymphocyte ratio $(\mathrm{NLR})=$ Neutrophil/lymphocyte, platelet to lymphocyte ratio (PLR) = platelet/lymphocyte, Prognostic nutritional index $(\mathrm{PNI})=\operatorname{lymphocyte}(/ \mu \mathrm{L}) \times 0.005+$ albumin $(\mathrm{g} / \mathrm{dL}) \times 10$, Systemic Immune-Inflammation Index (SII) = Neutrophil $\times$ platelet/lymphocyte.

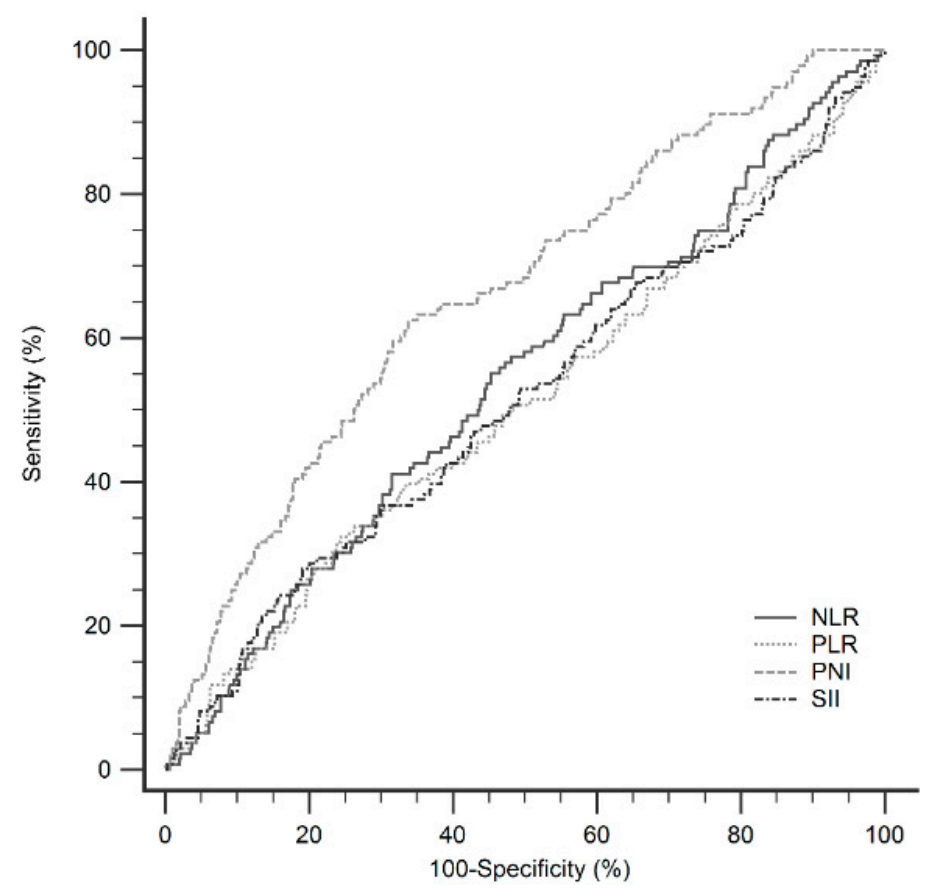

Figure 2. Comparisons of the areas under the curve (AUC) for outcome predictions in patients after operations.

\subsection{Survival Analysis}

The one- and five-year OS rates were 97 and $82 \%$, respectively. As shown in Table 3, old age ( $>60$ years old; $p=0.024)$, diabetes mellitus $(p<0.001)$, cirrhosis $(p<0.001)$, microvascular invasion $(p<$ $0.001)$, high AFP $(>5 \mu \mathrm{g} / \mathrm{L} ; p=0.047)$, high NLR $(>1.8 ; p=0.032)$, low PNI $(\leq 45 ; p<0.001)$, and low SII $(\leq 160 ; p=0.008)$ were associated with high OS in BCLC 0-A HCC patients after hepatectomy. The relationships of NLR, PNI, and SII with OS and RFS are shown in Figure 3. High NLR was significantly associated with poor OS ( $p=0.032)$. However, high PNI was significantly associated with better OS ( $p$ $<0.001)$ and RFS $(p<0.001)$. In addition, elevated SII was associated with better OS $(p=0.008)$ and RFS $(p<0.001)$. The one-year, three-year, and five-year OS rates of patients with PNI $>45$ and SII > 160 were $99 \%, 96 \%$, and $90 \%$ respectively, which were significantly higher than those observed with $\mathrm{PNI} \leq 45$ and $\mathrm{SII} \leq 160(90 \%, 77 \%$, and $66 \%)$ (Figure 4 ). 
Table 3. Cumulative survival rates in BCLC 0-A HCC patients after hepatectomy.

\begin{tabular}{|c|c|c|c|c|c|}
\hline Variables & Patient No. & 1 Year $(\%)$ & 3 Years $(\%)$ & 5 Years $(\%)$ & $p$ Value \\
\hline \multicolumn{6}{|l|}{ Age (Years) } \\
\hline$>60$ & 464 & 96.7 & 89.2 & 78.2 & 0.024 \\
\hline$\leq 60$ & 427 & 97.6 & 93.9 & 85.5 & \\
\hline \multicolumn{6}{|l|}{ Gender } \\
\hline Male & 694 & 96.9 & 92.0 & 82.4 & 0.792 \\
\hline Female & 197 & 98.0 & 89.3 & 79.4 & \\
\hline \multicolumn{6}{|c|}{ Diabetes Mellitus } \\
\hline Yes & 239 & 97.0 & 88.8 & 72.3 & $<0.001$ \\
\hline No & 621 & 97.1 & 92.5 & 84.9 & \\
\hline \multicolumn{6}{|l|}{ Liver Cirrhosis } \\
\hline Yes & 417 & 95.7 & 87.5 & 75.9 & $<0.001$ \\
\hline No & 474 & 98.5 & 94.9 & 86.8 & \\
\hline \multicolumn{6}{|l|}{ Differentiation } \\
\hline $\begin{array}{l}\text { Moderate or } \\
\text { Poor }\end{array}$ & 767 & 97.0 & 91.3 & 81.2 & 0.201 \\
\hline Well & 111 & 98.2 & 91.4 & 84.8 & \\
\hline \multicolumn{6}{|c|}{ Microvascular Invasion } \\
\hline Yes & 330 & 94.5 & 87,2 & 75.5 & $<0.001$ \\
\hline No & 561 & 98.7 & 94.0 & 85.3 & \\
\hline \multicolumn{6}{|c|}{ Serum AFP $(\mu g / L)$} \\
\hline$>5$ & 601 & 96.5 & 90.5 & 80.3 & 0.047 \\
\hline$\leq 5$ & 234 & 98.7 & 95.0 & 86.9 & \\
\hline \multicolumn{6}{|l|}{ NLR } \\
\hline 1.8 & 338 & 96.4 & 89.8 & 77.2 & 0.032 \\
\hline$\leq 1.8$ & 370 & 97.3 & 91.5 & 83.0 & \\
\hline \multicolumn{6}{|l|}{ PLR } \\
\hline 120 & 178 & 96.1 & 89.2 & 75.7 & 0.169 \\
\hline$\leq 120$ & 529 & 97.1 & 91.2 & 81.8 & \\
\hline \multicolumn{6}{|l|}{ PNI } \\
\hline 45 & 359 & 97.8 & 95.0 & 88.2 & 0.001 \\
\hline$\leq 45$ & 441 & 96.3 & 87.6 & 75.2 & \\
\hline \multicolumn{6}{|l|}{ SII $\left(\times 10^{9} / \mathrm{L}\right)$} \\
\hline 160 & 559 & 97.8 & 92.3 & 82.1 & 0.008 \\
\hline$\leq 160$ & 144 & 93.0 & 84.2 & 73.2 & \\
\hline
\end{tabular}

Abbreviations: HCC: hepatocellular carcinoma; AFP: alpha-fetoprotein; NLR: neutrophil-to-lymphocyte ratio; PLR: platelet to lymphocyte ratio; PNI: prognostic nutritional index; SII: systemic immune-inflammation index.

In the univariate analysis, old age ( $>60$ years old), HCV infection, HBV and HCV coinfection, diabetes mellitus, cirrhosis, microvascular infection, high AFP $(>5 \mu \mathrm{g} / \mathrm{L})$, high NLR $(>1.8)$, low PNI $(\leq 45)$, and low SII $\left(160 \times 10^{9} / \mathrm{L}\right)$ were associated with poor OS. The multivariate analysis of these parameters revealed that diabetes mellitus, cirrhosis, microvascular infection, low PNI $(\leq 45)$, and low SII $\left(\leq 160 \times 10^{9} / \mathrm{L}\right)$ were independently associated with poor OS. The HR of death for low PNI was 1.789 (95\% CI 1.217-2.630, $p=0.003)$, and that for low SII was 1.674 (95\% CI 1.097-2.552, $p=0.017)$ (Table 4$)$. 

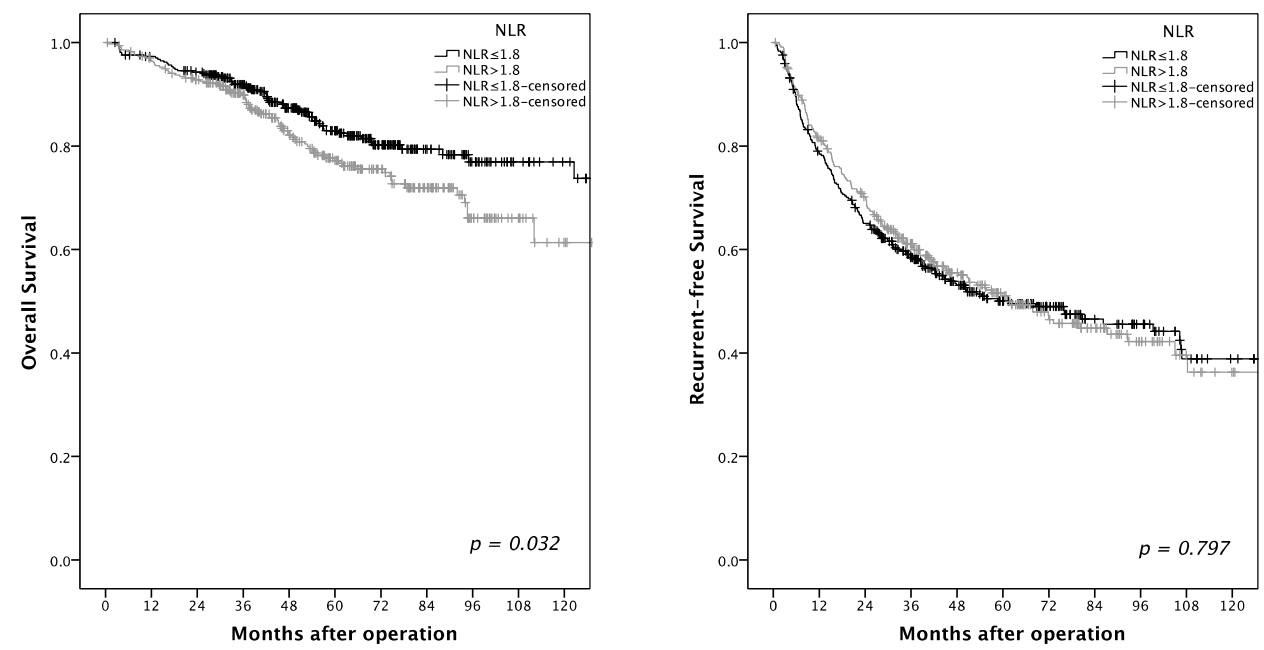

(A)
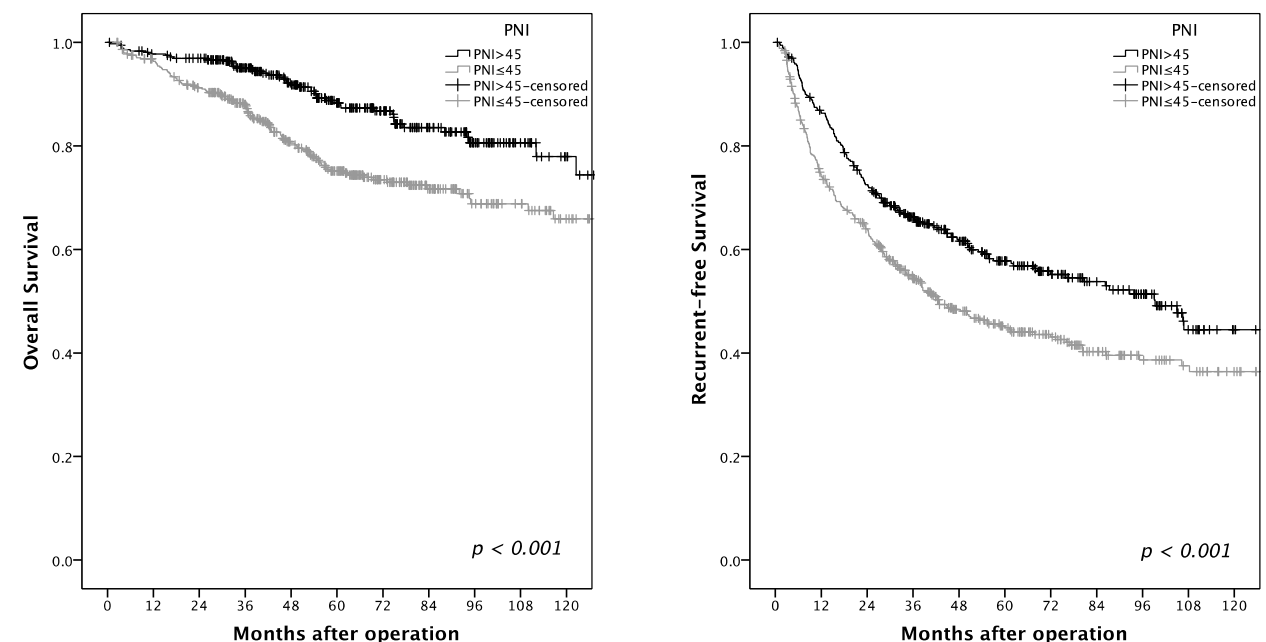

(B)
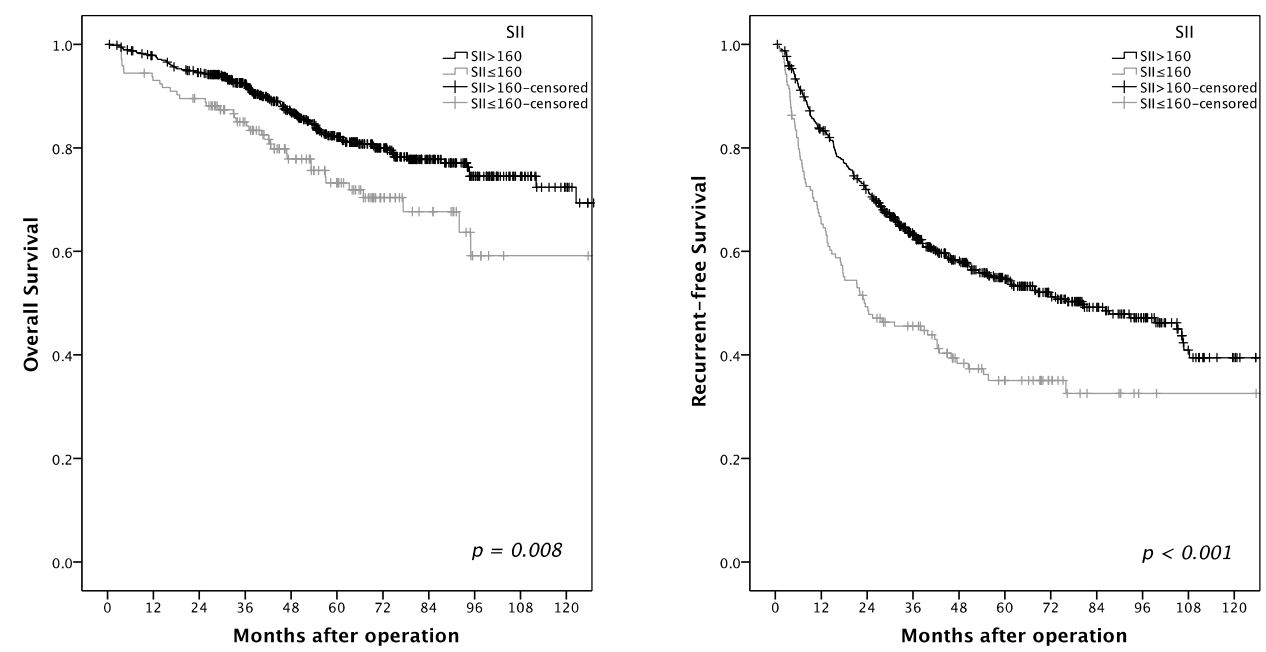

(C)

Figure 3. Relationship of (A) neutrophil-to-lymphocyte ratio (NLR), (B) prognostic nutrition index (PNI), and (C) systemic Immune-Inflammation Index (SII) to overall survival (OS), as well as recurrent free survival (RFS). 


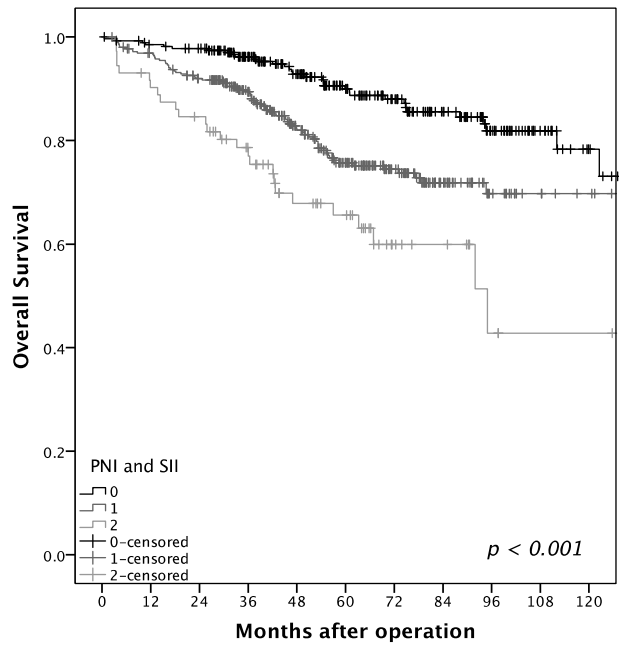

(A)

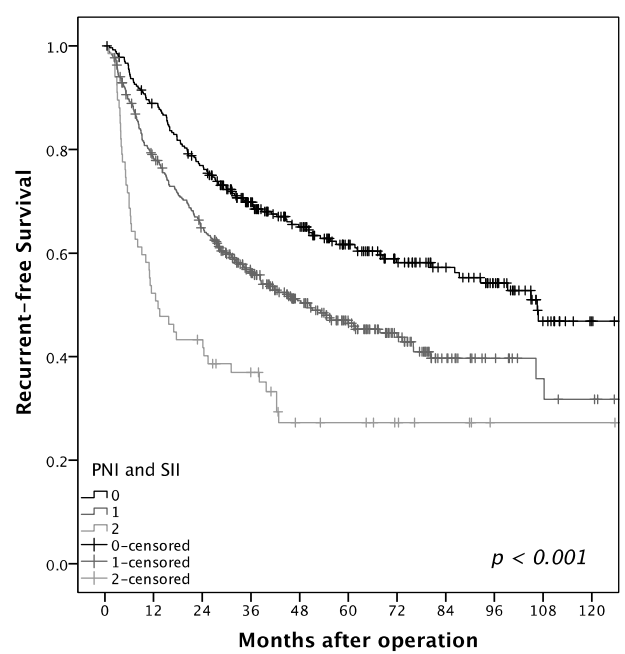

(B)

Figure 4. Relationship of prognostic nutrition index (PNI) and systemic Immune-Inflammation Index (SII) to (A) overall survival (OS) and (B) recurrence-free survival. Group $0=$ PNI $>45$ and SII $>160$, group $1=\mathrm{PNI}>45 / \mathrm{SII} \leq 160$ or $\mathrm{PNI} \leq 45 / \mathrm{SII}>160$, group $2=\mathrm{PNI} \leq 45$ and $\mathrm{SII} \leq 160$.

Table 4. Uni-and multivariate analyses of factors associated with mortality by Cox proportional hazards model.

\begin{tabular}{ccccccc}
\hline & \multicolumn{5}{c}{ Univariate } & \multicolumn{3}{c}{ Multivariate } \\
\cline { 2 - 7 } & HR & $\mathbf{9 5 \%}$ CI & $p$ Value & HR & 95\% CI & $p$ Value \\
\hline Male Sex & 1.050 & $0.728-1.516$ & 0.793 & & & \\
Age (60 Years) & 1.601 & $1.173-2.187$ & 0.003 & & & \\
HBV Infection & 0.922 & $0.562-1.514$ & 0.794 & & & \\
HCV Infection & 1.347 & $0.810-2.240$ & 0.251 & & & \\
HBV + HCV & 1.532 & $0.748-3.134$ & 0.243 & & & \\
Coinfection & 2.066 & $1.499-2.848$ & 0.001 & 1.989 & $1.362-2.906$ & 0.001 \\
Diabetes Mellitus & 1.978 & $1.442-2.713$ & 0.001 & 1.502 & $1.013-2.227$ & 0.043 \\
$\quad$ Cirrhosis & 1.367 & $0.836-2.235$ & 0.213 & & & \\
Moderate/poor & & & & & \\
Differentiation & 2.040 & $1.427-2.915$ & 0.001 & 1.642 & $1.123-2.401$ & 0.011 \\
Microvascular & & & & & \\
Invasion & 1.541 & $1.044-2.276$ & 0.030 & & & \\
AFP 5 $\mu$ g/L & 1.441 & $1.029-1.071$ & 0.033 & & & \\
$\quad$ NLR 1.8 & 1.287 & $0.898-1.845$ & 0.170 & & & \\
PLR 120 & 1.976 & $1.401-2.788$ & 0.001 & 1.789 & $1.217-2.630$ & 0.003 \\
PNI $\leq 45$ & 1.654 & $1.137-2.405$ & 0.008 & 1.674 & $1.097-2.552$ & 0.017 \\
SII $\leq 160(\times 109 / \mathrm{L})$ &
\end{tabular}

Abbreviations: HR: hazard ratio; CI: confidence interval; HBV: hepatitis B virus; HCV: hepatitis C virus; AFP: alpha-fetoprotein; NLR: neutrophil-to-lymphocyte ratio; PLR: platelet to lymphocyte ratio; PNI: prognostic nutritional index; SII: systemic immune-inflammation index.

Overall, 458 patients (51.4\%) were free from tumor relapse during the follow-up period, and the mean time to recurrence was $3.80 \pm 3.17$ years. The one- and five-year RFS rates were 80 and $51 \%$, respectively. The univariate analysis showed that poor RFS was also associated with old age ( $>60$ years old), HCV infection, HBV and HCV coinfection, diabetes mellitus, cirrhosis, microvascular invasion, high AFP $(>5 \mu \mathrm{g} / \mathrm{L})$, low PNI $(\leq 45)$, and SII $\left(\leq 160 \times 10^{9} / \mathrm{L}\right)$. The multivariate analysis demonstrated that HCV infection, diabetes mellitus, cirrhosis, microvascular invasion, low PNI $(\leq 45)$, and low SII $\left(\leq 160 \times 10^{9} / \mathrm{L}\right)$ were independent prognostic factors for RFS. The HR of tumor recurrence for low PNI 
was $1.378(95 \%$ CI 1.092-1.738, $p=0.007)$, and that for low SII was $1.616(95 \%$ CI 1.231-2.123, $p=0.001)$ (Table 5).

Table 5. Uni- and multivariate analyses of factors associated with recurrence by Cox proportional hazards model.

\begin{tabular}{|c|c|c|c|c|c|c|}
\hline & \multicolumn{3}{|c|}{ Univariate } & \multicolumn{3}{|c|}{ Multivariate } \\
\hline & HR & $95 \% \mathrm{CI}$ & $p$ Value & HR & $95 \% \mathrm{CI}$ & $p$ Value \\
\hline Male Sex & 0.978 & $0.779-1.228$ & 0.848 & & & \\
\hline Age (60 Years) & 1.382 & $1.144-1.670$ & 0.001 & & & \\
\hline HBV Infection & 1.214 & $0.885-1.665$ & 0.230 & & & \\
\hline HCV Infection & 1.651 & $1.189-2.293$ & 0.003 & 1.298 & $1.022-1.649$ & 0.033 \\
\hline $\begin{array}{l}\mathrm{HBV}+\mathrm{HCV} \\
\text { Coinfection }\end{array}$ & 1.880 & $1.164-3.036$ & 0.010 & & & \\
\hline Diabetes Mellitus & 1.368 & $1.110-1.687$ & 0.003 & 1.352 & $1.05-1.734$ & 0.017 \\
\hline Cirrhosis & 1.762 & $1.457-2.132$ & 0.001 & 1.536 & $1.21-1.950$ & 0.001 \\
\hline $\begin{array}{l}\text { Moderate/Poor } \\
\text { Differentiation }\end{array}$ & 1.005 & $0.760-1.329$ & 0.972 & & & \\
\hline $\begin{array}{l}\text { Microvascular } \\
\text { Invasion }\end{array}$ & 1.653 & $1.325-2.062$ & 0.001 & 1.542 & $1.218-1.951$ & 0.001 \\
\hline AFP $5 \mu \mathrm{g} / \mathrm{L}$ & 1.398 & $1.116-1.752$ & 0.004 & & & \\
\hline NLR 1.8 & 0.972 & $0.786-1.203$ & 0.797 & & & \\
\hline PLR 120 & 0.975 & $0.765-1.243$ & 0.839 & & & \\
\hline $\mathrm{PNI} \leq 45$ & 1.462 & $1.195-1.790$ & 0.001 & 1.378 & $1.092-1.738$ & 0.007 \\
\hline $\mathrm{SII} \leq 160\left(\times 10^{9} / \mathrm{L}\right)$ & 1.751 & $1.372-2.234$ & 0.001 & 1.616 & $1.231-2.123$ & 0.001 \\
\hline
\end{tabular}

Abbreviations: HR: hazard ratio; CI: confidence interval; HBV: hepatitis B virus; HCV: hepatitis C virus; AFP: alpha-fetoprotein; NLR: neutrophil-to-lymphocyte ratio; PLR: platelet to lymphocyte ratio; PNI: prognostic nutritional index; SII: systemic immune-inflammation index.

The relationship between inflammatory markers and clinicopathological features is summarized in Table 6; Table 7. Low PNI $(\leq 45)$ was associated with old age $(p<0.001)$, HCV infection $(p<0.001)$, raised alanine aminotransferase (ALT) $(p<0.001)$, decreased albumin $(p<0.001)$, and raised INR $(p<$ $0.001)$. SII $\leq 160$ was associated with raised INR $(p<0.001)$ and microvascular invasion $(p=0.034)$.

Table 6. Comparison of characteristics between patients with high and low PNI.

\begin{tabular}{cccc}
\hline & High PNI $(\mathbf{4 5}, \boldsymbol{n = 3 6 2 )}$ & Low PNI $(\leq \mathbf{4 5}, \boldsymbol{n = 4 4 4 )}$ & $p$ Value \\
\hline Male Sex & $294(81.2 \%)$ & $338(76.1 \%)$ & 0.086 \\
Age, Years & $55.67 \pm 12.23$ & $60.83 \pm 10.79$ & 0.001 \\
HBV Infection & $228(63.0 \%)$ & $230(51.8 \%)$ & 0.002 \\
HCV Infection & $95(26.2 \%)$ & $187(42.1 \%)$ & 0.001 \\
APRI & $0.61 \pm 0.47$ & $1.24 \pm 2.01$ & 0.001 \\
ALT, U/L & $42.24 \pm 26.79$ & $63.61 \pm 103.31$ & 0.001 \\
Neutrophil, $/ \mu \mathrm{L}$ & $3240.26 \pm 1210.93$ & $4181.64 \pm 3668.09$ & 0.001 \\
Lymphocyte, $/ \mu \mathrm{L}$ & $2109.12 \pm 641.08$ & $1445.07 \pm 560.36$ & 0.001 \\
Platelet, $\times 10^{3} / \mu \mathrm{L}$ & $170.90 \pm 55.62$ & $151.95 \pm 89.63$ & 0.001 \\
Total Bilirubin, mg/dL & $0.80 \pm 0.30$ & $0.83 \pm 0.36$ & 0.171 \\
Albumin, g/dL & $4.07 \pm 0.40$ & $3.30 \pm 0.54$ & 0.001 \\
Prothrombin Time, INR & $1.02 \pm 0.056$ & $1.05 \pm 0.96$ & 0.001 \\
Moderate/Poor & $314(89.0 \%)$ & $376(85.6 \%)$ & 0.200 \\
Differentiation & $130(46.4 \%)$ & $158(48.9 \%)$ & 0.568 \\
Microvascular Invasion & $416.47 \pm 1620.65$ & $661.87 \pm 3242.02$ & 0.195 \\
AFP, $\mu \mathrm{g} / \mathrm{L}$ & &
\end{tabular}

Data are expressed as mean \pm standard deviation or number (percentage). Abbreviations: PNI: prognostic nutritional index; HBV: hepatitis B virus; HCV: hepatitis C virus; APRI: aspartate aminotransferase to platelet ratio index; ALT: alanine aminotransferase; INR: international normalized ratio; AFP: alpha-fetoprotein. 
Table 7. Comparison of characteristics between patients with high and low SII.

\begin{tabular}{cccc}
\hline & High SII $(\mathbf{1 6 0}, \boldsymbol{n}=\mathbf{5 5 9 )}$ & Low SII $(\leq \mathbf{1 6 0}, \boldsymbol{n}=\mathbf{1 4 4})$ & $\boldsymbol{p}$ Value \\
\hline Male Sex & $452(80.9 \%)$ & $101(70.1 \%)$ & 0.006 \\
Age, Years & $58.87 \pm 11.66$ & $58.41 \pm 11.46$ & 0.672 \\
HBV Infection & $316(56.5 \%)$ & $81(56.3 \%)$ & 1.000 \\
HCV Infection & $191(34.2 \%)$ & $60(41.7 \%)$ & 0.098 \\
APRI & $0.84 \pm 1.60$ & $1.32 \pm 1.00$ & 0.001 \\
ALT, U/L & $53.62 \pm 91.86$ & $56.50 \pm 39.24$ & 0.714 \\
Neutrophil, $/ \mu \mathrm{L}$ & $4193.03 \pm 2970.90$ & $2004.19 \pm 611.43$ & 0.001 \\
Lymphocyte, $/ \mu \mathrm{L}$ & $1713.61 \pm 651.65$ & $1977.01 \pm 780.13$ & 0.001 \\
Platelet, $\times 10^{3} / \mu \mathrm{L}$ & $171.02 \pm 80.96$ & $115.46 \pm 41.09$ & 0.001 \\
Total bilirubin, mg/dL & $0.80 \pm 0.34$ & $0.81 \pm 0.30$ & 0.822 \\
Albumin, $\mathrm{g} / \mathrm{dL}$ & $3.62 \pm 0.61$ & $3.50 \pm 0.60$ & 0.054 \\
Prothrombin Time, INR & $1.03 \pm 0.07$ & $1.06 \pm 0.10$ & 0.001 \\
Moderate/Poor & $480(87.9 \%)$ & $131(91.0 \%)$ & 0.377 \\
Differentiation & $211(53.0 \%)$ & $67(65.0 \%)$ & 0.034 \\
Microvascular Invasion & $516.49 \pm 2293.49$ & $873.22 \pm 4145.54$ & 0.175 \\
AFP, $\mu \mathrm{g} / \mathrm{L}$ &
\end{tabular}

Data are expressed as mean \pm standard deviation or number (percentage). Abbreviations: SII: systemic immune-inflammation index; HBV: hepatitis B virus; HCV: hepatitis C virus; APRI: aspartate aminotransferase to platelet ratio index; ALT: alanine aminotransferase; INR: international normalized ratio; AFP: alpha-fetoprotein.

\section{Discussion}

Surgical resection is the mainstay of curative treatment for very-early and early-stage HCC with preserved liver function. Tumor recurrence is still the main concern of resection, and the five-year cumulative HCC recurrent rates are more than 50\% [2,28]. Many studies have shown the relationships between inflammatory response and the development of tumors, and several scoring systems have been developed to predict the prognosis in cancer patients. NLR, PLR, PNI, and SII have been reported to be useful in predicting OS and recurrence in HCC patients.

We investigated the clinical and prognostic value of these widely used inflammatory markers in early-stage HCC patients receiving operation and compared their predictive accuracy. Our retrospective cohort of 891 patients revealed that PNI and SII are independent predictors of OS and tumor recurrence. Furthermore, the predictive power of the PNI score outweighs that of other inflammatory markers. PNI and SII are derived from routinely available blood tests, making them easy to apply in routine clinical practice to predict the prognosis in HCC patients.

Studies have shown that the systemic inflammatory response as measured by the NLR, PLR, and SII are good predictors of tumor outcomes. The exact mechanism remains unclear, but several hypotheses have been proposed. Basic studies have revealed that neutrophils can induce tumor proliferation and angiogenesis, as well as enhance the migration and metastasis of cancer cells. In addition, HCC cells induce neutrophils to release hepatocyte growth factor, which makes cancer cells become more aggressive [29]. Platelets can be activated by immune cells and cancer cells and play an important role in tumor metastasis, tumor growth, and angiogenesis. This occurs by protecting cancer cells from immune surveillance, facilitating cancer cell arrest within the vasculature and subsequent tissue invasion, inducing endothelial cell proliferation and new blood vessel formation, and interacting with cancer cells and stroma in the tumor microenvironment [30]. However, lymphocytes, including $\mathrm{T}$ cells, B cells, and natural killer cells, have antitumor effects either directly or upon the activation of other lymphocytes [31].

Higher levels of NLR and PLR are associated with poor outcomes in many types of cancer. In a meta-analysis of patients with HCC, Zeng et al. examined 24 studies and concluded that a high NLR predicted a poor OS (HR: 1.54, 95\% CI 1.34-1.76, $p<0.001$ ) and poor RFS (HR: 1.45, 95\% CI 1.16-1.82, $p=0.001$ ), while a high PLR predicted poor OS (HR: 1.63, 95\% CI 1.34-1.98, $p<0.001$ ) and poor RFS (HR: 1.52, 95\% CI 1.21-1.91, $p<0.001$ ) [32]. In the present study, a high NLR $(>1.8)$ before surgical 
resection predicted poor OS in HCC patients, but NLR was not an independent factor in predicting OS and RFS in the multivariate analyses. PLR had no significant association with OS or RFS.

Higher SII has been reported to be a poor prognostic factor in multiple cancers. A recent meta-analysis included 22 studies with 7657 patients and showed that a higher level of SII was correlated with poor OS (HR: $1.69,95 \%$ CI 1.42-2.01, $p<0.001$ ) and poor RFS (HR $=1.66, p=0.025$ ) in patients with cancers. Furthermore, a subgroup analysis revealed that higher SII than a cutoff value could predict poor OS in HCC $(p<0.001)$ [33]. However, our study revealed the opposite result: low SII predicted a poor prognosis of OS (HR: 1.674, 95\% CI 1.097-2.552, $p=0.017$ ) and RFS (HR: 1.616, 95\% CI: 1.231-2.123, $p=0.001$ ). Lower SII means lower neutrophil levels, lower platelet levels, and higher lymphocyte levels, as shown in Table 7. Thrombocytopenia was an independent predictor for survival in patients with compensated cirrhosis and HCC treated with hepatectomy [34]. Through a meta-analysis, Zhang et al. showed that thrombocytopenia in HCC patients was associated with poor OS (HR: 1.47, 95\% CI 1.21-1.78) and poor RFS (HR: 1.41, 95\% CI: 1.22-1.62) in HCC patients after hepatic resection [35]. Platelet count has been used to assess the severity of chronic liver disease and features of portal hypertension [36]. In the present study, low SII was associated with high APRI and high INR, which are related to significant fibrosis and poor liver function. In the subgroup analysis stratified by platelet count, low SII in the thrombocytopenia group revealed significantly poor OS $(p=$ $0.019)$ and RFS ( $p=0.002)$ compared to those with high SII, but there was no statistical significance in the non-thrombocytopenia group. Therefore, low SII is associated with poor outcome due to advanced liver disease, especially in those with thrombocytopenia.

The PNI was initially designed to assess the immunological and nutritional condition of patients undergoing surgery for digestive diseases [37]. It was first used to predict HCC outcome as an inflammatory marker by Pinato et al. in 2012 [18]. Lymphopenia is an unfavorable prognostic factor for OS in several cancers [38], which may result from an increased rate of turnover of lymphocytes induced by tumor cells [39] or an altered homeostasis of lymphocytes in patients with tumors [40]. Albumin synthesis is reduced by the systemic inflammatory response to a tumor [41], although impaired hepatic synthetic function in advanced liver disease also needs to be considered as an additional cause for reduced serum albumin. Chan et al. reported that the PNI was a significant predictor for OS and RFS in patients with very-early/early-stage HCC receiving curative surgery [20]. Our data are consistent with previous studies suggesting that low PNI predicts poor OS and RFS in HCC patients receiving hepatectomy. We subsequently compared the predictive power of the PNI with other inflammatory markers, including NLR, PLR, and SII, and the PNI produced superior results.

Nevertheless, there are some limitations to our study. First, it is a retrospective study with patients from a single institution, which could lead to biases. Second, more than half of the patients in the study had HBV infection as the etiology of HCC, whereas chronic HCV infection is the major cause for the development of HCC in Western countries and Japan [42]. Moreover, laboratory values were only collected before surgery, and a serial follow-up of inflammatory markers after surgery may provide more insights in the prognostic values.

In conclusion, among the evaluated preoperative serum inflammatory markers, low PNI and low SII were independently associated with unfavorable outcomes of OS and RFS in patients with BCLC 0-A hepatocellular carcinoma after hepatectomy. Those observed with low PNI or low SII, especially $\mathrm{PNI} \leq 45$ and SII $\leq 160$ with a high one-year recurrence rate $(50 \%)$, need a close follow-up, and further adjuvant therapies, such as target or immune-based therapy, might be required. However, the side effects of drugs should be watched for, and additional well-designed studies are needed to confirm this concept. Further evaluation of these markers should be performed on a larger scale and compared between different patient populations.

Author Contributions: Conceptualization, T.-H.H. and M.-C.T.; Data curation, C.-C.W., C.-C.L., S.-N.L., J.-H.W., C.-H.H., K.-M.K., C.-H.C., K.-D.C. and T.-H.H.; Methodology, M.-C.T.; Supervision, M.-C.T.; Writing-original draft, P.-Y.H.; Writing-review \& editing, M.-C.T. 
Funding: This study was supported by grants from Chang Gung Memorial Hospital (Grant numbers: CMRPG8F1671 and CMRPG890161)

Acknowledgments: We thank the Biostatistics Center, Kaohsiung Chang Gung Memorial Hospital, for the statistical work.

Conflicts of Interest: There are no conflicts of interest to disclose for all authors.

\section{Abbreviations}

HCC hepatocellular carcinoma

NLR neutrophil-to-lymphocyte ratio

PLR platelet to lymphocyte ratio

PNI prognostic nutritional index

SII systemic immune-inflammation index

\section{References}

1. Bray, F.; Ferlay, J.; Soerjomataram, I.; Siegel, R.L.; Torre, L.A.; Jemal, A. Global cancer statistics 2018: GLOBOCAN estimates of incidence and mortality worldwide for 36 cancers in 185 countries. CA Cancer J. Clin. 2018, 68, 394-424. [CrossRef] [PubMed]

2. Heimbach, J.K.; Kulik, L.M.; Finn, R.S.; Sirlin, C.B.; Abecassis, M.M.; Roberts, L.R.; Zhu, A.X.; Murad, M.H.; Marrero, J.A. AASLD guidelines for the treatment of hepatocellular carcinoma. Hepatology 2018, 67, 358-380. [CrossRef] [PubMed]

3. Omata, M.; Cheng, A.-L.; Kokudo, N.; Kudo, M.; Lee, J.M.; Jia, J.; Tateishi, R.; Han, K.-H.; Chawla, Y.K.; Shiina, S.; et al. Asia-Pacific clinical practice guidelines on the management of hepatocellular carcinoma: A 2017 update. Hepatol. Int. 2017, 11, 317-370. [CrossRef] [PubMed]

4. Ercolani, G.; Grazi, G.L.; Ravaioli, M.; del Gaudio, M.; Gardini, A.; Cescon, M.; Varotti, G.; Cetta, F.; Vavallari, A. Liver resection for hepatocellular carcinoma on cirrhosis: Univariate and multivariate analysis of risk factors for intrahepatic recurrence. Ann. Surg. 2003, 237, 536-543. [CrossRef] [PubMed]

5. Forner, A.; Llovet, J.M.; Bruix, J. Hepatocellular carcinoma. Lancet 2012, 379, 1245-1255. [CrossRef]

6. Tabrizian, P.; Jibara, G.; Shrager, B.; Schwartz, M.; Roayaie, S. Recurrence of hepatocellular cancer after resection: Patterns, treatments, and prognosis. Ann. Surg. 2015, 261, 947-955. [CrossRef]

7. Hirokawa, F.; Hayashi, M.; Asakuma, M.; Shimizu, T.; Inoue, Y.; Uchiyama, K. Risk factors and patterns of early recurrence after curative hepatectomy for hepatocellular carcinoma. Surg. Oncol. 2016, 25, 24-29. [CrossRef]

8. Zheng, J.; Kuk, D.; Gönen, M.; Balachandran, V.P.; Kingham, T.P.; Allen, P.J.; D'Angelica, M.I.; Jarnagin, W.R.; DeMatteo, R.P. Actual 10-Year Survivors After Resection of Hepatocellular Carcinoma. Ann. Surg. Oncol. 2017, 24, 1358-1366. [CrossRef]

9. Grivennikov, S.I.; Greten, F.R.; Karin, M. Immunity, inflammation, and cancer. Cell 2010, 140, $883-899$. [CrossRef]

10. Mantovani, A.; Allavena, P.; Sica, A.; Balkwill, F. Cancer-related inflammation. Nature 2008, 454, 436-444. [CrossRef]

11. Qi, X.; Li, J.; Deng, H.; Li, H.; Su, C.; Guo, X. Neutrophil-to-lymphocyte ratio for the prognostic assessment of hepatocellular carcinoma: A systematic review and meta-analysis of observational studies. Oncotarget 2016, 7, 45283-45301. [CrossRef] [PubMed]

12. Chen, T.-M.; Lin, C.-C.; Huang, P.-T.; Wen, C.-F. Neutrophil-to-lymphocyte ratio associated with mortality in early hepatocellular carcinoma patients after radiofrequency ablation. J. Gastroenterol. Hepatol. 2012, 27, 553-561. [CrossRef] [PubMed]

13. McNally, M.E.; Martinez, A.; Khabiri, H.; Guy, G.; Michaels, A.J.; Hanje, J.; Kirkpatrick, R.; Bloomston, M.; Schmidt, C.R. Inflammatory markers are associated with outcome in patients with unresectable hepatocellular carcinoma undergoing transarterial chemoembolization. Ann. Surg. Oncol. 2013, 20, 923-928. [CrossRef] [PubMed]

14. Liu, C.; Jia, B.-S.; Zou, B.-W.; Du, H.; Yan, L.-N.; Yang, J.-Y.; Jiang, L.; Wen, T.-F.; Wang, W.-T.; Xu, M.-Q.; et al. Neutrophil-to-lymphocyte and aspartate-to-alanine aminotransferase ratios predict hepatocellular carcinoma prognosis after transarterial embolization. Medicine (Baltimore) 2017, 96, e8512. [CrossRef] [PubMed] 
15. Shen, S.-L.; Fu, S.-J.; Chen, B.; Kuang, M.; Li, S.-Q.; Hua, Y.-P.; Liang, L.-J.; Guo, P.; Hao, Y.; Peng, B.-G. Preoperative Aspartate Aminotransferase to Platelet Ratio is an Independent Prognostic Factor for Hepatitis B-Induced Hepatocellular Carcinoma After Hepatic Resection. Ann. Surg. Oncol. 2014, 21, 3802-3809. [CrossRef] [PubMed]

16. Zhao, Y.; Si, G.; Zhu, F.; Hui, J.; Cai, S.; Huang, C.; Cheng, S.; Fathy, A.H.; Xiang, Y.; Li, J. Prognostic role of platelet to lymphocyte ratio in hepatocellular carcinoma: A systematic review and meta-analysis. Oncotarget 2017, 8, 22854-22862. [CrossRef] [PubMed]

17. Wang, Y.; Attar, B.M.; Fuentes, H.E.; Jaiswal, P.; Tafur, A.J. Evaluation of the prognostic value of platelet to lymphocyte ratio in patients with hepatocellular carcinoma. J. Gastrointest. Oncol. 2017, 8, 1065-1071. [CrossRef] [PubMed]

18. Pinato, D.J.; North, B.V.; Sharma, R. A novel, externally validated inflammation-based prognostic algorithm in hepatocellular carcinoma: The prognostic nutritional index (PNI). Br. J. Cancer 2012, 106, 1439-1445. [CrossRef]

19. Nagai, S.; Mangus, R.S.; Kubal, C.A.; Ekser, B.; Fridell, J.A.; Klingler, K.R.; Maluccio, M.A.; Tector, A.J. Prognosis after recurrence of hepatocellular carcinoma in liver transplantation: Predictors for successful treatment and survival. Clin. Transplant. 2015, 29, 1156-1163. [CrossRef]

20. Chan, A.W.H.; Chan, S.L.; Wong, G.L.H.; Wong, V.W.S.; Chong, C.C.N.; Lai, P.B.S.; Chan, H.L.Y.; To, K.-F. Prognostic Nutritional Index (PNI) Predicts Tumor Recurrence of Very Early/Early Stage Hepatocellular Carcinoma After Surgical Resection. Ann. Surg. Oncol. 2015, 22, 4138-4148. [CrossRef]

21. Pinato, D.; Stebbing, J.; Ishizuka, M.; Khan, S.; Wasan, H.; North, B.; Kubota, K.; Sharma, R. A novel and validated prognostic index in hepatocellular carcinoma: The inflammation based index (IBI). J. Hepatol. 2012, 57, 1013-1020. [CrossRef] [PubMed]

22. Li, M.X.; Bi, X.Y.; Li, Z.Y.; Huang, Z.; Han, Y.; Zhou, J.; Zhao, J.; Zhang, Y.; Zhao, H.; Cai, J. Prognostic Role of Glasgow Prognostic Score in Patients With Hepatocellular Carcinoma: A Systematic Review and Meta-Analysis. Medicine (Baltimore) 2015, 94, e2133. [CrossRef] [PubMed]

23. Bruix, J.; Sherman, M. American Association for the Study of Liver D. Management of hepatocellular carcinoma: An update. Hepatology 2011, 53, 1020-1022. [CrossRef] [PubMed]

24. Llovet, J.; Bru, C.; Bruix, J. Prognosis of Hepatocellular Carcinoma: The BCLC Staging Classification. Semin. Liver Dis. 1999, 19, 329-338. [CrossRef] [PubMed]

25. Villanueva, A. Hepatocellular Carcinoma. N. Engl. J. Med. 2019, 380, 1450-1462. [CrossRef] [PubMed]

26. Nozoe, T.; Ninomiya, M.; Maeda, T.; Matsukuma, A.; Nakashima, H.; Ezaki, T. Prognostic nutritional Index: A tool to predict the biological aggressiveness of gastric carcinoma. Surg. Today 2010, 40, 440-443. [CrossRef]

27. Asselah, T.; Marcellin, P.; Bedossa, P. Improving performance of liver biopsy in fibrosis assessment. J. Hepatol. 2014, 61, 193-195. [CrossRef] [PubMed]

28. Pompili, M.; Saviano, A.; de Matthaeis, N.; Cucchetti, A.; Ardito, F.; Federico, B.; Brunello, F.; Pinna, A.D.; Giorgio, A.; Giulini, S.M.; et al. Long-term effectiveness of resection and radiofrequency ablation for single hepatocellular carcinoma $\leq 3 \mathrm{~cm}$. Results of a multicenter Italian survey. J. Hepatol. 2013, 59, 89-97. [CrossRef]

29. Uribe-Querol, E.; Rosales, C. Neutrophils in Cancer: Two Sides of the Same Coin. J. Immunol. Res. 2015, 2015, 983698. [CrossRef]

30. Bambace, N.M.; Holmes, C.E. The platelet contribution to cancer progression. J. Thromb. Haemost. 2011, 9 , 237-249. [CrossRef]

31. Mossanen, J.C.; Tacke, F. Role of lymphocytes in liver cancer. OncoImmunology 2013, 2, e26468. [CrossRef] [PubMed]

32. Zheng, J.; Cai, J.; Li, H.; Zeng, K.; He, L.; Fu, H.; Zhang, J.; Chen, L.; Yao, J.; Zhang, Y.; et al. Neutrophil to Lymphocyte Ratio and Platelet to Lymphocyte Ratio as Prognostic Predictors for Hepatocellular Carcinoma Patients with Various Treatments: A Meta-Analysis and Systematic Review. Cell. Physiol. Biochem. 2017, 44, 967-981. [CrossRef] [PubMed]

33. Yang, R.; Chang, Q.; Meng, X.; Gao, N.; Wang, W. Prognostic value of Systemic immune-inflammation index in cancer: A meta-analysis. J. Cancer 2018, 9, 3295-3302. [CrossRef] [PubMed]

34. Roayaie, S.; Obeidat, K.; Sposito, C.; Mariani, L.; Bhoori, S.; Pellegrinelli, A.; Labow, D.; Llovet, J.M.; Schwartz, M.; Mazzaferro, V.M. Resection of hepatocellular cancer $\leq 2 \mathrm{~cm}$ : Results from two Western centers. Hepatology 2013, 57, 1426-1435. [CrossRef] [PubMed] 
35. Zhang, Z.; Zhang, Y.; Wang, W.; Hua, Y.; Liu, L.; Shen, S.; Peng, B. Thrombocytopenia and the outcomes of hepatectomy for hepatocellular carcinoma: A meta-analysis. J. Surg. Res. 2017, 210, 99-107. [CrossRef] [PubMed]

36. Giannini, E.G. Thrombocytopenia in patients with chronic liver disease: What's in a name? Dig. Dis. Sci. 2013, 58, 299-301. [CrossRef]

37. Nozoe, T.; Kimura, Y.; Ishida, M.; Saeki, H.; Korenaga, D.; Sugimachi, K. Correlation of pre-operative nutritional condition with post-operative complications in surgical treatment for oesophageal carcinoma. Eur. J. Surg. Oncol. (EJSO) 2002, 28, 396-400. [CrossRef]

38. Ray-Coquard, I.; Cropet, C.; Van Glabbeke, M.; Sebban, C.; Le Cesne, A.; Judson, I.; Tredan, O.; Verweij, J.; Biron, P.; Labidi, I.; et al. Lymphopenia as a prognostic factor for overall survival in advanced carcinomas, sarcomas, and lymphomas. Cancer Res. 2009, 69, 5383-5391. [CrossRef]

39. Zhang, B.; Sun, T.; Xue, L.; Han, X.; Zhang, B.; Lu, N.; Shi, Y.; Tan, W.; Zhou, Y.; Zhao, D.; et al. Functional polymorphisms in FAS and FASL contribute to increased apoptosis of tumor infiltration lymphocytes and risk of breast cancer. Carcinogenesis 2007, 28, 1067-1073. [CrossRef]

40. Goldrath, A.W.; Bevan, M.J. Selecting and maintaining a diverse T-cell repertoire. Nature 1999, 402, $255-262$. [CrossRef]

41. McMillan, D.C.; Watson, W.S.; O'Gorman, P.; Preston, T.; Scott, H.R.; McArdle, C.S. Albumin Concentrations are Primarily Determined by the Body Cell Mass and the Systemic Inflammatory Response in Cancer Patients with Weight Loss. Nutr. Cancer 2001, 39, 210-213. [CrossRef] [PubMed]

42. El-Serag, H.B.; Rudolph, K.L. Hepatocellular Carcinoma: Epidemiology and Molecular Carcinogenesis. Gastroenterology 2007, 132, 2557-2576. [CrossRef] [PubMed]

(C) 2019 by the authors. Licensee MDPI, Basel, Switzerland. This article is an open access article distributed under the terms and conditions of the Creative Commons Attribution (CC BY) license (http://creativecommons.org/licenses/by/4.0/). 